\title{
Electroless Copper Deposition Using Saccharose Containing Copper Methane Sulphonate Bath with Thiourea as Stabilizer
}

\author{
P. BALARAMESH ${ }^{1}$, S. REKHA ${ }^{2}$, P. VENKATESH ${ }^{3}$ and S.SHANMUGAN ${ }^{4 *}$ \\ ${ }^{1}$ RMK Engineering College, RSM Nagar, Kavaraipettai, Chennai, Tamilnadu, India \\ ${ }^{2}$ RMD Engineering College, RSM Nagar, Kavaraipettai, Chennai, Tamilnadu, India \\ ${ }^{3}$ Pachayaippa's College, Chennai, Tamilnadu, India \\ ${ }^{4}$ Nano Optoelectronics Research Laboratory, School of Physics, \\ Universiti Sains, Malaysia (USM), 11800, Minden, Pulau Pinang, Malaysia \\ shagan77in@yahoo.co.in
}

Received 28 February 2014 / Revised 18 March 2014 / Accepted 26 March 2014

\begin{abstract}
Electroless copper deposition is used in the fabrication of integrated circuit (IC) interconnections, micro-electro-mechanical systems (MEMS) devices and printed circuit board (PCBs). In order to meet the long term usage of chemical bath for electroless deposition, an ecofriendly copper methane sulphonate (CuMS) was used to prepare the chemical bath for $\mathrm{Cu}$ deposit. The deposition parameters such as temperature, $\mathrm{pH}, \mathrm{Cu}$ ion concentration and para-formaldehyde concentration were optimized at $28^{\circ} \mathrm{C}$ with $3 \mathrm{~g} / \mathrm{L}$ of CuMS, $10 \mathrm{~g} / \mathrm{L}$ of para-formaldehyde for the $\mathrm{pH}$ of 12.75.The deposition rate was increased for high concentration of $\mathrm{Cu}$ and para-formaldehyde in the chemical bath. Highly stable bath was achieved at $28{ }^{\circ} \mathrm{C}$ with $1 \mathrm{ppm}$ thiourea content and produced uniform $\mathrm{Cu}$ film surface with larger grains. Good quality and (200) oriented $\mathrm{Cu}$ thin film with larger crystallite size was observed with $1 \mathrm{ppm}$ thiourea added bath.
\end{abstract}

Keywords: Electroless deposition. Copper methane sulphonate, Stable bath, Saccharose, Thiourea

\section{Introduction}

Provide a seed layer on a dielectric material for subsequent acid copper electroplating ${ }^{1-2}$. The main advantage electroless copper plating is widely used for the fabrication of printed circuit boards and other electronic devices. Electroless copper can also of this technique is a possibility to plate nonconductive surfaces and to obtain metal coatings of the uniform thickness over the plated object. In addition, the allowable current density for electroless deposited copper is typically $10^{3}$ greater compared to typical solder connections ${ }^{3-4}$. Also it has superior mechanical properties compared to solder, such as yield stress and Young's modulus. These mechanical values, along with the ability to fabricate high aspect ratio connections, can be used to form mechanically compliant interconnect structures.

Furthermore, electroless plating requires more rigorous control because of transient bath changes and the mechanical properties of the deposit are highly dependent on process parameters. 
The deposition rate of $\mathrm{Cu}$ thin film and their properties are depending on the copper complexing agent, reducing agent, temperature and $\mathrm{pH}$ of the bath ${ }^{5}$. Thus, further investigations are necessary for the electroless copper plating process to meet the specific requirements.Various complex agents have been used in electroless copper plating namely xylitol, D-mannitol and D- sorbitol and accounted as the most environment friendly alternative to copper(II) ligand in chemical bath solution. Electroless copper plating solutions containing the chelators such as xylitol, D-mannitol and D-sorbitol are stable and under optimal conditions, copper coatings up to $3 \mu \mathrm{m}$ thick can be obtained in $1 \mathrm{~h}$ at ambient temperatures $^{6-7}$. In this study, a new bath is prepared in which copper sulphate is replaced by copper methane sulphonate. The copper methane sulphonate contains saccharose (CuMSsa $\left.(\mathrm{OH})_{3}{ }^{2-}\right)$ reacts with formaldehyde and produces $\mathrm{Cu}$ thin film on $\mathrm{Cu}$ substrates. The complex reaction is as given below:

$$
\mathrm{CuMSsa}(\mathrm{OH})_{3}{ }^{2-}+2 \mathrm{HCHO}+\mathrm{OH}^{-} \rightarrow \mathrm{Cu}+\mathrm{H}_{2}+2 \mathrm{HCOO}^{-}+\mathrm{H}_{2} \mathrm{O}+\mathrm{MSsa}^{-}
$$

In this study, saccharose containing $\mathrm{Cu}$ (II) ions is used as ligand instead of other complexing ligands since $\mathrm{Cu}(\mathrm{II})-$ saccharose is an eco-friendly ligand ${ }^{8}$. Methane sulphonic acid or methane sulphonate (MSA) has gained more popularity in electronic industries for electroless copper plating. It is also characterized by excellent metal salt solubility, conductivity, bath stability, bio-degradability and also helps to produce uniform high quality coating ${ }^{9}$. In addition, it is also an eco-friendly agent due to the ease of effluent treatment and less toxicity. Norcus et al. have already investigated the $\mathrm{CuSa}(\mathrm{OH})_{3}{ }^{2-}$ complex as the principal electro active species in the catalytic reaction ${ }^{10}$. Still it is necessary to understand the influence of process parameters on the film quality for desired application. This paper describes the bath optimization process and influence of plating parameters such as $\mathrm{pH}$, concentration of $\mathrm{Cu}$ and reducing agent and bath temperature on the deposition rate as well as surface properties of $\mathrm{Cu}$ thin film.

\section{Experimental}

Environment friendly copper bath was prepared by using MSA, Saccharose, p-formaldehyde, potassium hydroxide $(\mathrm{KOH})$ (to vary the $\mathrm{pH}$ of the bath) and thiourea. The electroless $\mathrm{Cu}$ deposition was performed on $\mathrm{Cu}$ sheet $(2.0 \times 2.0 \times 0.1 \mathrm{~cm})$ in $100 \mathrm{~mL}$ beaker. Prior to deposit, the $\mathrm{Cu}$ substrate was rinsed with double distilled water after polishing process with fine grid paper. Figure 1 shows the flow chart of the methodology of electroless $\mathrm{Cu}$ thin film deposition.

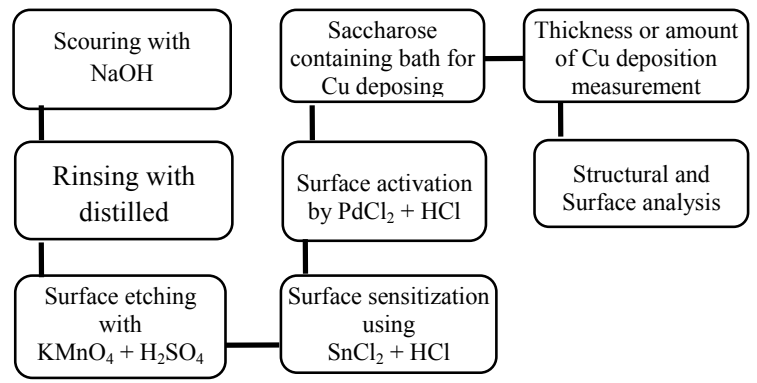

Figure 1. Systematic flow diagram for the eco-friendly preparation of electroless $\mathrm{Cu}$ deposition

Proper surface pretreatment of the substrate is more important to achieve smooth and compact deposits. For good adhesive property, the substrate was processed for degreasing using $2 \mathrm{M}$ - sodium hydroxide at $60^{\circ} \mathrm{C}$ for 2 minutes and rinsed with cold water followed by 
etching process with $10 \%$ sulfuric acid $\left(\mathrm{H}_{2} \mathrm{SO}_{4}\right)$ added potassium permanganate $\left(\mathrm{KMnO}_{4}\right)$ for about $1 \mathrm{~min}$. After rinsing with distilled water, the substrate was processed for shipley process described in the literature ${ }^{11}$.

In order to make the surface sensitive for $\mathrm{Cu}$ deposition, hydrochloric acid mixed stannous chloride solution was prepared and immersed the substrate for 1 min followed by the surface activation process using palladium chloride solution mixed with hydrochloric acid. Finally, the substrate was rinsed with distilled water for special catalytic effect and deposition too.

\section{Electroless Cu deposition}

The processed $\mathrm{Cu}$ substrate was fed into $100 \mathrm{~mL}$ beaker containing the $\mathrm{Cu}(\mathrm{II})$ ion complex and left for $60 \mathrm{~min}$ to conduct the electroless deposition. The temperature of the bath was maintained at $30{ }^{\circ} \mathrm{C}$. In order to prepare the stock solution, about $50 \mathrm{~g}$ of copper carbonate was weighed and transferred into $500 \mathrm{~mL}$ clean beaker. The copper carbonate was treated with $60 \mathrm{~mL}$ of MSA until the evaluation of $\mathrm{CO}_{2}$ gas. In order to make $250 \mathrm{~mL}$ capacity, required double distilled water was added into treated solution and stored in standard measuring flask. Before storing the stock solution, the observed oil and suspended impurities during the preparation was removed by filtration. The amount of $\mathrm{Cu}$ present in the stock solution was evaluated by analyzing $1 \mathrm{~mL}$ of stock solution with $\mathrm{N} / 10$ of standard sodium thiosulphate solution. The amount of deposited $\mathrm{Cu}$ was calculated using mass difference basis calculation. All measurements were repeated for more than three times in order to maintain the accuracy.The rate of deposition $(\mathrm{T})$ is calculated using the following relation:

$$
\mathrm{T}=\mathrm{W} \times 10^{4} / \mathrm{dAt}
$$

Where $\mathrm{W}$ is the mass of the deposit $(\mathrm{g}), \mathrm{d}$ is the density of the film material $\left(\mathrm{g} / \mathrm{cm}^{3}\right), \mathrm{A}$ is the area of the film coated $\left(\mathrm{cm}^{2}\right)$ and $\mathrm{t}$ is the coating duration (hr).

\section{Properties of electroless $\mathrm{Cu}$ thin film}

The Xray Diffraction technique (Xpert-Pro, Panalytical) was used to identify the structural properties such as crystalline size and quality of the plated $\mathrm{Cu}$. The surface topography of electroless $\mathrm{Cu}$ was evaluated using Carlzeiss MA-150 make Scanning Electron Microscope (SEM). In addition, Atomic Force Microscope (AFM) (NanoSurf Easy Scan2, Switzerland) was also used to analyze the surface roughness of the $\mathrm{Cu}$ deposit.

\section{Results and Discussion}

\section{Structural properties}

The structural quality of the $\mathrm{Cu}$ thin film deposited using eco-friendly chemical bath was tested using XRD technique and observed the spectra as given in Figure 2. The inset Figure in Figure 2 shows the XRD spectrum of pure $\mathrm{Cu}$ metal substrates. it is observed that the intensity of the XRD peak is low for pure copper. It shows the influence of stabilizer on structural quality of the $\mathrm{Cu}$ thin film. In this study, we used thiourea as stabilizer. Figure 2 clearly indicates that (200) oriented peak shows high intensity for plain bath than thiourea added bath. In addition, the full with half maximum (FWHM) of (200) oriented peak is low compared to plain bath. Moreover, in our sample, the predominant (111) oriented peak ${ }^{12}$ from pure $\mathrm{Cu}$ is also observed with low intensity when compared to (200) oriented peak. The $\mathrm{Cu}(111) / \mathrm{Cu}(200)$ intensity ratio is also calculated and shows high value $(0.137)$ for $\mathrm{Cu}$ thin film prepared form thiourea added bath than plain bath $(0.095)$. Lee et al. ${ }^{13}$ have already reported the high intensity of (200) oriented peak from copper methane sulphonate bath in presence of more $\mathrm{Cu}$ ions. It is attributed to highly conductive and solubility behavior of the 
prepared $\mathrm{Cu}$ thin film. The intensity of (111) oriented peak slightly increases for thiourea added samples. Overall, the $\mathrm{Cu}$ thin film prepared by chemical bath has good crystalline nature than the pure $\mathrm{Cu}$ substrate (inset Figure 2).

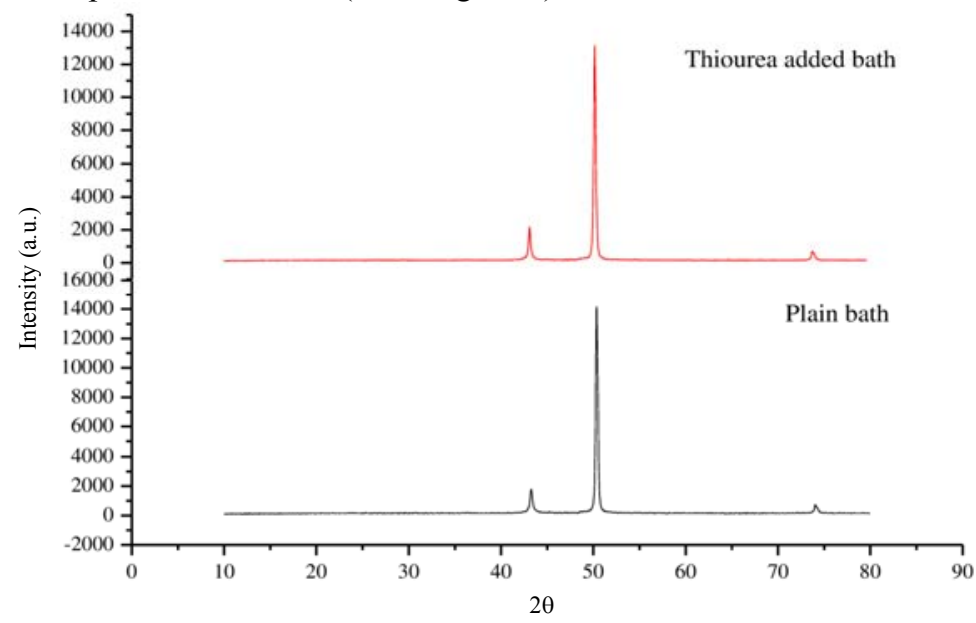

Figure 2. XRD spectra of elctroless deposited $\mathrm{Cu}$ thin film from plain and thiourea added bath

Figure 2 also evidenced the synthesis of high crystalline quality $\mathrm{Cu}$ thin film using ecofriendly chemical bath. In order to examine the crystalline size of the $\mathrm{Cu}$ thin film, the size of the crystals (D) is calculated by using Debye-Scherrer's equation ${ }^{14-15}$.

$$
\mathrm{D}=\mathrm{K} \lambda / \beta \cos \theta
$$

Where, $\lambda$ is wavelength of $\mathrm{Cu} \mathrm{K \alpha}, \beta$-Breadth of diffracted line (i.e) FWHM (rad), $\theta-$ Bragg angle of diffracted rays, $\mathrm{K}-$ Constant (0.89). From the equation 2, the calculated crystallite size of plain and thiourea added bath is about $98 \mathrm{~nm}$ and $135 \mathrm{~nm}$ respectively.

\section{Influence of bath parameters on $\mathrm{Cu}$ deposition rate}

The influence of preparation parameters such as $\mathrm{pH}$, concentration of $\mathrm{Cu}$ ion and $\mathrm{p}$ formaldehyde concentration on the $\mathrm{Cu}$ deposition are presented in Table 1. It shows that the rate of $\mathrm{Cu}$ deposition increases for the increase of both concentration of $\mathrm{Cu}$ ion and $\mathrm{p}$ formaldehyde in the chemical bath. In addition, it is also observed from Table 1 that the $\mathrm{pH}$ of the bath also influences highly on the deposition rate and observed high value of 2.87 $\mu \mathrm{m} / \mathrm{h}$ at $12.75 \mathrm{pH}$. The non-liner behavior is noticed with the deposition rate as it increases initially and decreases noticeably with $\mathrm{pH}$ value increases. Since we used $\mathrm{KOH}$ as to maintain the $\mathrm{pH}$ of the bath, the deposition was observed only after $\mathrm{pH}=12$. After several experiment, based on the stable condition, the bath was optimized at $3 \mathrm{~g} / \mathrm{L}$ of copper methane sulphonate and $10 \mathrm{~g} / \mathrm{L}$ of $p$-formaldehyde at $\mathrm{pH}=12.75$.

In addition to this, the stability of prepared bath was also tested for various temperatures and the results are given in Table 2. It reveals that the deposition rate increases with the temperature of bath increases. It is observed that the bath attains stable up to $40{ }^{\circ} \mathrm{C}$ and produces $\mathrm{Cu}$ thin film at $3.45 \mu \mathrm{m} / \mathrm{h}$ rate. But it is also noticed that the bath at $50{ }^{\circ} \mathrm{C}$ shows high deposition rate but unstable. Based on the literature ${ }^{16}$, the chemical bath without stabilizer was unstable at longer experiments and poorly reproducible. To solve this, additives have been proposed to improve the ductility of electroless copper films ${ }^{17}$. 
Table 1. Influence of $\mathrm{Cu}$ ion concentration, $\mathrm{pH}$ and reducing agent on the rate of $\mathrm{Cu}$ deposition in electroless coating

\begin{tabular}{cccccc}
\hline \multicolumn{2}{c}{$\begin{array}{c}\text { Effect of concentration of } \\
\text { copper, } \mathrm{g} / \mathrm{L}\end{array}$} & \multicolumn{2}{c}{ Effect of $\mathrm{pH}$} & \multicolumn{2}{c}{ Effect of reducing agent } \\
\hline $\begin{array}{c}\text { Concentration of } \\
\text { copper, } \mathrm{g} / \mathrm{L} \text { ) }\end{array}$ & $\begin{array}{c}\text { Deposition } \\
\text { rate, } \mu \mathrm{m} / \mathrm{h}\end{array}$ & $\mathrm{pH}$ & $\begin{array}{c}\text { Deposition } \\
\text { rate, } \mu \mathrm{m} / \mathrm{h}\end{array}$ & $\begin{array}{c}\text { Para- } \\
\text { formaldehyde, } \mathrm{g} / \mathrm{L}\end{array}$ & $\begin{array}{c}\text { Deposition } \\
\text { rate, } \mu \mathrm{m} / \mathrm{h}\end{array}$ \\
\hline 1 & 0.78 & 12.25 & 1.25 & 1 & 0.86 \\
2 & 1.74 & 12.50 & 2.50 & 5 & 2.14 \\
3 & 2.87 & 12.75 & 2.87 & 10 & 2.87 \\
4 & 3.78 & 13.0 & 2.14 & 15 & 3.92 \\
5 & 5.03 & 13.25 & 1.60 & 20 & 4.20 \\
\hline
\end{tabular}

Table 2. Influence of temperature on deposition rate of $\mathrm{Cu}$ in electroless coating.

\begin{tabular}{ccc}
\hline Temperature, ${ }^{\circ} \mathrm{C}$ & Deposition rate, $\mu \mathrm{m} / \mathrm{h}$ & Bath condition \\
\hline 28 & 2.87 & Stable \\
35 & 3.02 & Stable \\
40 & 3.45 & Stable \\
45 & 4.31 & Less Stable \\
50 & 6.32 & Unstable \\
\hline
\end{tabular}

As we discussed above, the thiourea was used as a stabilizer and the influence of stabilizer content on the deposition rate was also tested. The composition of thiourea is also given in Table 3. The observed deposition rate with respect to thiourea content is plotted in Figure 3. It shows that the concentration of thiourea in the bath highly affects the deposition rate as it increases with thiourea content decreases.

Table 3. Composition of chemical bath used for electroless $\mathrm{Cu}$ deposition

\begin{tabular}{ccc}
\hline Bath Contains & Plain bath & Thiourea concentration \\
\hline CuMS(II) ion contacting salt & $3 \mathrm{~g} / \mathrm{L}$ & $3 \mathrm{~g} / \mathrm{L}$ \\
Saccharose & $20 \mathrm{~g} / \mathrm{L}$ & $20 \mathrm{~g} / \mathrm{L}$ \\
HCHO & $10 \mathrm{~g} / \mathrm{L}$ & $10 \mathrm{~g} / \mathrm{L}$ \\
$\mathrm{pH}$ & 12.75 & 12.75 \\
Thiourea & $0 \mathrm{ppm}$ & $1 \mathrm{ppm}$ \\
\hline
\end{tabular}

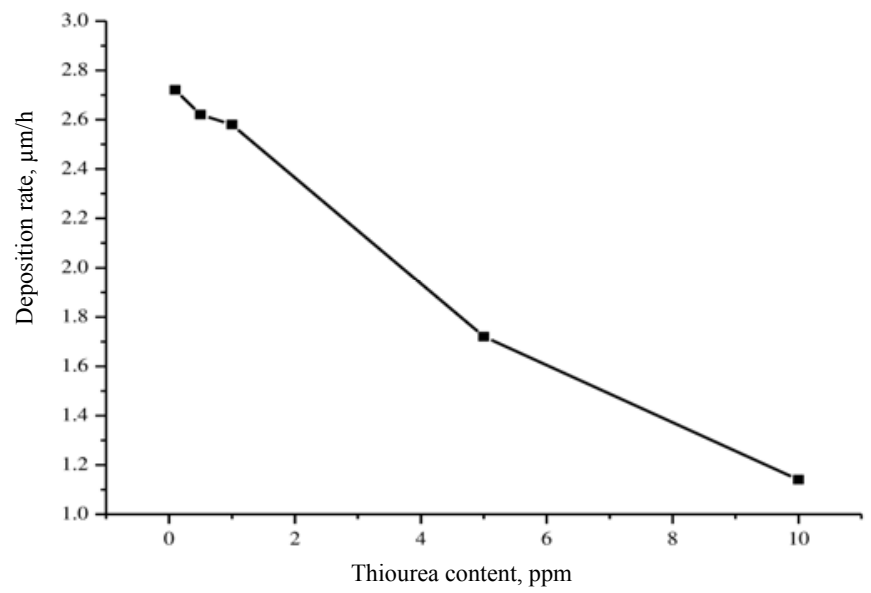

Figure 3. Influence of thiourea content in chemical bath on the rate of $\mathrm{Cu}$ deposition. 


\section{Surface morphology}

To examine the surface morphology, the SEM images of electroless deposited $\mathrm{Cu}$ were recorded as given in Figure 4 (a-b). Figure 4a shows the surface morphology of $\mathrm{Cu}$ deposit in plain bath which reveals uniform surface morphology with small grains agglomeration on top of the surface. The particle size of the $\mathrm{Cu}$ deposit is also measured using the SEM software and observed between 0.8 and $1 \mu \mathrm{m}$. From Figure $4 \mathrm{a}$, the loosely bounded particles could also be observed on top surface of the film and reveals the less dense nature of the $\mathrm{Cu}$ thin film. Figure $4 \mathrm{~b}$ shows the surface morphology of $\mathrm{Cu}$ deposit in presence of $1 \mathrm{ppm}$ thiourea and shows uniform surface with larger grains size. It is also observed that the film density is comparatively higher than the plain bath. It clearly indicates the film structure as the combination of large grains. In order to study the surface roughness, AFM images of the $\mathrm{Cu}$ thin film prepared with and without thiourea are also recorded and presented in Figure 5(a - b). The 3D images of respective thin films are also observed as given in the same Figure 5 (right side column). Figure 5a reveals the surface topography of $\mathrm{Cu}$ thin film prepared using plain bath and observed roughness of about $340 \mathrm{~nm}$. It also reveals the loosely bounded particles on surface of $\mathrm{Cu}$ deposit. But a noticeable reduction on surface roughness could be observed with thiourea added chemical bath as $167 \mathrm{~nm}$ and exhibited the dense nature of film surface.

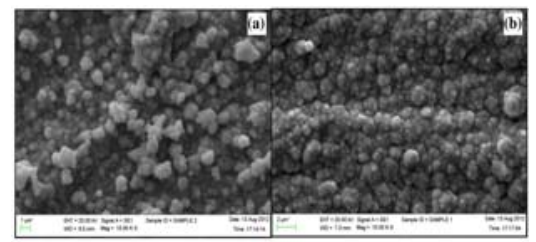

Figure 4. SEM images of electroless deposited $\mathrm{Cu}$ using (a) plain bath and (b) $1 \mathrm{ppm}$ thiourea added bath.

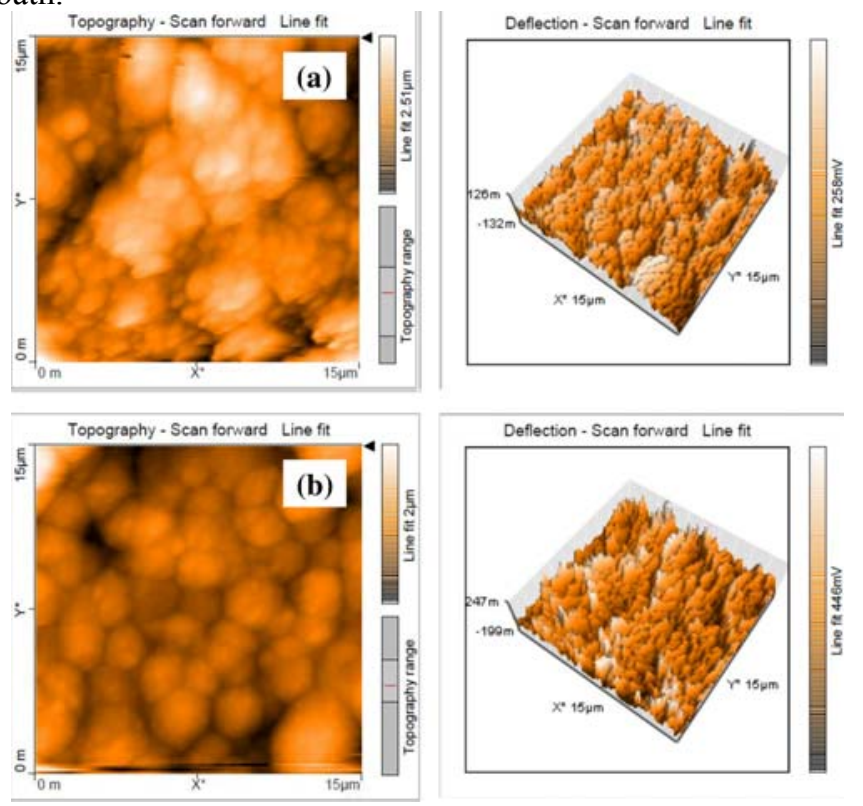

Figure 5. AFM images of electroless deposited $\mathrm{Cu}$ using (a) plain bath and (b) 1 ppm thiourea added bath. 


\section{Conclusion}

Eco-friendly copper methane sulphonate containing chemical bath was prepared for electroless $\mathrm{Cu}$ deposition. The deposition parameters such as bath temperature, $\mathrm{pH}$, concentration of $\mathrm{Cu}$ ions and reducing agent were influenced the rate of $\mathrm{Cu}$ deposition. $2.87 \mu \mathrm{m}$ of $\mathrm{Cu}$ deposit was achieved with the optimized bath. Stable bath was achieved with $1 \mathrm{ppm}$ of thiourea and observed $2.72 \mu \mathrm{m}$ thickness of $\mathrm{Cu}$ in an hour. Intensive (200) oriented $\mathrm{Cu}$ phase with increased crystallite size was observed with thiourea added bath. Increased bath life and decreased deposition was achieved with high concentration of thiourea. Uniform and dense $\mathrm{Cu}$ thin film surface was achieved with thiourea added bath.

\section{References}

1. Tseng W T, Lo C H, and Lee S C, J Electrochem Soc., 2001, 148, 327-332; DOI:10.1149/1.1359200.

2. Yung E K and Romankiw L T J Electrochem Soc, 1989, 136, 206; DOI:10.1149/1.2096587

3. Choi W J,Yeh E C and Tu K N, J Appl Phys., 2003, 94, 5665.

4. Tao J, Cheung N W, Hu C, Kang H K and Wong S S, IEEE Electron Device Lett., 1992, 13, 433.

5. Duffy J, Pearson L and Paunovic M, J Electrochem Soc., 1983, 130, 876.

6. Norcus E, Vaskelis A, Jaciauskiene J, Vaiciuniene J, Gaidamauskas E and Macalady D L, J Appl Electrochem., 2005, 35, 41-47.

7. Norkus E, Vaiciuniene J, Vuorinen T, Gaidamauskas E, Reklaitis J, Jaskelainen A S and Crans D C, Carbohydr Res., 2004, 339, 599-605; DOI: 10.1016/j.carres.2003.12.003

8. Norkus E, Prusinskas K, Vaskelis A, Jaciauskiene J, Stalnioniene L and Macalady D L, Carbohydr Res., 2007, 342, 71-78; DOI: 10.1016/j.carres.2006.10.020

9. Rekha S, Srinivasan K N and John S, Trans Inst Met Finish., 2010, 88, 215-219.

10. Norkus E, Pauliukaite R and Vaskelis A, J Chem Res.(s), 1998, 6, 320-321.

11. Shipley C R Jr. "Method of Electroless Deposition on a Substrate and Catalyst Solution Therefor" United States Patent, 1961, 3011920.

12. Junginger R and Elsner G, J Electrochem Soc.1988, 135, 2304; DOI: 10.1149/1.2096258

13. Lee D N, J Korean Inst Engg., 1996, 29, 301.

14. Mastsuoka M, Murai J and Iwakura C, J Electrochem Soc., 1992, 139, 2466.

15. Cullity B D, Element of X-ray diffraction, Addison-Wesley, London, 1978.

16. Paunivic M, Plating, 1968, 55, 1161.

17. Paunivic M and Arundt R, J Eletrochem Soc, 1983, 130, 794; DOI: 10.1149/1.2119806 